\title{
Resin composites direct odontal bulk fill technique in posterior teeth - case report
}

\author{
Tehnica de restaurare odontală directă în masă ( "bulk fill") cu răşini compozite \\ în zona laterală - prezentare de caz
}

\author{
Iulian Băluță1, Irina-Maria Gheorghiu², Paula Perlea ${ }^{3}$, Anca Nicoleta Temelcea ${ }^{4}$, \\ Sânziana Scărlătescu ${ }^{3}$ \\ ${ }^{1}$ Dentist, Clinica Privată, Bucureşti, România \\ ${ }^{2}$ Disciplina Odontoterapie Restauratoare, Facultatea de Medicină Dentară, \\ Universitatea de Medicină şi Farmacie „Carol Davila“, Bucureşti, România \\ ${ }^{3}$ Disciplina Endodonţie, Facultatea de Medicină Dentară, Universitatea de Medicină şi Farmacie \\ „Carol Davila“, Bucureşti, România \\ ${ }^{4}$ Disciplina Tehnica Dentară, Facultatea de Moaşe şi Asistenţă Medicală, \\ Universitatea de Medicină şi Farmacie „Carol Davila“, Bucureşti, România
}

\begin{abstract}
This article presents a modern technique in the field of direct dental restorations using composite resins. The wide variety of clinical situations we have encountered has forced the development of multiple modalities and materials to restore the loss of dental hard substance in the posterior areas. Among these, the bulk-fill technique, in which specific low-consistency composites are used, leads to a correct obturation in terms of marginal sealing, mechan-ical strength, and reduced risk of occurrence of postoperative sensitivity.
\end{abstract}

Keywords: odontal restoration, resin composites, "bulk fill" technique

\section{REZUMAT}

Articolul de faţă prezintă o tehnică modernă în domeniul restaurărior dentare directe cu ajutorul răşinilor compozite. Marea varietate a situaţiilor clinice cu care ne confruntăm a impus apariţia şi dezvoltarea unor multiple modalităţi şi materiale de refacere a pierderilor de substanţă dură dentară din zonele posterioare. Între acestea, tehnica “ în masă” ("bulk-fill”), în care sunt utilizate compozite specifice, cu consistenţă scăzută, conduce la realizarea unei obturaţii corecte din punct de vedere al sigilării marginale, rezistenţei mecanice, cât şi a diminuării riscului de apariţie a sensibilităţii postoperatorii.

Cuvinte cheie: restaurare odontală, răşini compozite, tehnica „în masă“

\section{INTRODUCERE}

Articolul de faţă trece în revistă modalităţiile actuale de restaurare odontală a zonei posterioare, luând în consideraţie importanţa restaurărilor directe atât pentru sănătatea orală, cât şi pentru cea a întregului organism. Tehnicile şi mijloacele de restaurare sunt alese, în primul rând în funcţie de defectul dentar de structură existent, apoi în funcţie de dotă- rile, exigenţele şi capacităţile medicului stomato$\log$, în vederea efectuării unei restaurări corecte.

Abordarea terapeutică a zonei posterioare se realizează în raport cu etiologia pierderii de substanţă, cantitatea de substanţă dură restantă, poziţia dintelui pe arcadă, valoarea solicitărilor funcţionale, exigenţele estetice, resursele pacientului, dar în acelaşi timp şi în raport cu gradul de perfecţionare al medicului şi dotările cabinetului de medicină dentară. 
Modalităţile de tratament în zona laterală, în scopul refacerii integrităţii arcadelor dentare, se realizează cu ajutorul restaurărilor directe (obturaţii) sau a restaurărilor indirecte (incrustaţii sau microproteze), în funcţie de severitatea pierderii de substanţă dură dentară. De asemenea, această restaurare morfofuncţională poate implica şi tratamente endodontice care decurg din posibilele afectări pulpare şi periapicale (1). Atunci când dintele este irecuperabil, soluţia este aceea a realizării tratamentului chirurgical radical, şi anume, extracţia dintelui atunci când metodele chirurgicale conservatoare, cum ar fi rezecţia apicală, chiuretajul periapical sau premolarizarea sunt depăşite. Rezecţia apicală are o indicaţie destul de restrânsă pentru zona posterioară, aceasta se poate efectua în special la nivelul premolarilor inferiori. Premolarizarea sau amputaţia radiculară se realizează la dinţii pluriradiculari (molari superiori şi inferiori).

\section{Restaurările odontale directe}

Restaurările odontale din zona posterioară au în vedere în primul rând restabilirea funcţiei masticatorii, aşadar acestea trebuie să suporte solicitările funcţionale ale aparatului dento-maxilar, în special solicitările ocluzale. Materialele de restaurare directă moderne (răşini compozite, cimenturi cu ionomeri de sticlă), prezintă atât proprietăţi biomecanice (rezistenţă la fractură şi uzură), cât şi proprietăţi estetice (stabilitate coloristică, fotomimetism, disponibilitate într-un număr foarte mare de nuanţe), capabile să îndeplinească astfel cerinţele estetice şi funcţionale (2).

Răşinile compozite sunt cele mai utilizate materiale în restaurările directe. Acestea necesită un sacrificiu minim de substanţă dentară, având adeziune mecano-chimică. Răşinile compozite fotopolimerizabile, se pot manipula pentru o perioadă lungă de timp, fiind ideale pentru aplicare şi modelaj, iar datorită varietăţii de nuanţe coloristice împreună cu avantajele prezentate, se pot obţine rezultate foarte bune estetice (3).

Marea varietate a situaţiilor clinice cu care ne confruntăm a impus apariţia şi dezvoltarea unor diferite tehnici de refacere a pierderilor de substanţă dura dentară din zonele posterioare. Printre acestea menţionăm: tehnica stratificării, tehnica sandwich, tehnica bulk fill, tehnica centripetă, tehnica morfologică. Alegerea uneia dintre tehnicile menţionate se face după ce clinicianul a reevaluat anumite aspecte, cum ar fi prepararea cavităţii (preparaţie de tip adeziv), extinderea spaţială a cavităţii, atât în suprafaţă, cât şi în profunzime, izolarea (ideal cu ajutorul digii dentare), tehnica de inserare a materialui de restaurare, modalitatea optimă de realizarea a contururilor proximale, a punctului de contact şi a morfologiei ocluzale (4). De asemenea, se urmăresc atât diminuarea contracţiei de polimerizare, cât şi facilitarea modelării şi obţinerea unui rezultat morfo-funcţional corespunzător. În acelsi timp, tehnica aleasă trebuie să fie simplă, puţin consumatoare de timp şi cu un rezultat predictibil $(5,6)$.

\section{Tehnica de inserare „în masă“" (“bulk fill”)}

Tendinţa actuală în restaurarea directă din zona posterioară este de reducere a numărului de straturi de compozit, atât pentru a diminua contracţia de polimerizare, cât şi din punctul de vedere al ergonomiei (tehnică simplă, rapidă şi eficientă). Astfel, tehnica „în masă“( (“bulk-fill”) îndeplineşte ambele criterii, oferind o restaurare directă corectă în privinţa sigilării marginale, rezistenţei mecanice a obturatiei, cât şi a diminuării riscului de apariţie a sensibilităţii postoperatorii (7).

Această tehnică se realizează cu ajutorul compozitelor fluide( flow), cu consistenţă mai mică decât cele condensabile ("condensable"/"packable"), aceasta fiind ,cremoasă“". Consistenţa acestor compozite permite materialului să curgă uşor, să se întindă uniform şi să se adapteze intim la forma cavităţii. Astfel, cu ajutorul tehnicii bulk fill, stresul provocat de contracţia de polimerizare este cu aproximativ $60 \%$ mai redus faţă de tehnica stratificării, această permiţând o fotopolimerizare controlată şi, de asemenea, o umplere de până la 4 mm faţă de standardul de $2 \mathrm{~mm}$, necesar la celelalte compozite pentru a putea permite fotopolimerizarea cum ar fi în tehnica clasică a stratificării (8). Indicaţiile acestei tehnici sunt pentru cavităţile profunde de clasa I şi a II-a, cât şi ca restaurare directă posterioară în coroborare cu tehnica ştanţării. Compozitele fluide specifice tehnicii bulk fill se mai pot folosi în cavităţile preventive, după enameloplastie, cavităţi clasa I ultraconservatoare, precum şi pentru obturarea cavităţilor modificate pentru leziunile proximale ale dinţilor laterali de tip ,,casetă“, „slot“, ,şanţ“, ,,jgheab“, „,unel“ sau ,galerie“. 
Aceste compozite fluide se pot folosi chiar şi pentru reparaţiile unor restaurări indirecte din ceramică/compozit de dimensiuni reduse.

Răşinile compozite de acest tip( exemplu: SDR (Smart Dentin Replacement), Dentsply ${ }^{\circledR}$; Filtek Bulk Fill ${ }^{\circledR}, 3 \mathrm{M}$ ESPE; Tetric N-Flow Bulk Fill@, Ivoclar Vivadent) sunt caracterizate printr-o contracţie de polimerizare redusă, previn microinfiltraţia, iar tensiunile de la interfaţă sunt contracarate de elasticitatea materialului (9). De asemenea, acestea permit o fotopolimerizare pe o grosime de cel puţin $4 \mathrm{~mm}$, comparativ cu fotopolimerizarea compozitului packable $(2 \mathrm{~mm})$. Un avantaj important al acestor materiale este acela că permit o conductibilitate a fasciculului luminos astfel încât transluciditatea este deosebită, dar mai prezintă şi avantajul de avea rezistenţă mare la compresiune şi abraziune $(10,11)$.

\section{PREZENTARE DE CAZ}

În articolul de faţă prezentăm modalitatea de refacere coronară directă, cu ajutorul materialelor compozite, prin tehnica bulk fill, a unui proces carios localizat la nivelul dintelui 36, la un pacient în vârstă de 28 ani (Fig. 1). La examentul obiectiv a fost evidenţiată prezenţa leziunii carioase în şanţurile şi fosetetele ocluzale, precum şi în şanţul vestibular de descărcare şi foseta vestibulară, iar anamneza pacientului a evidenţiat antecedente heredocolaterale şi antecedente personale patologice irelevante pentru tratament.

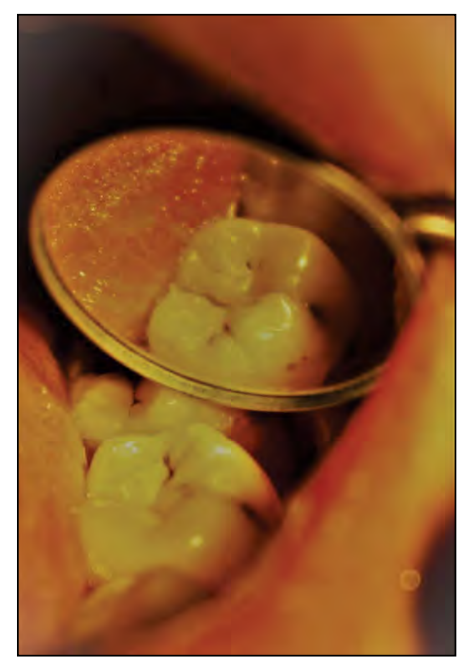

FIGURA 1. Leziune carioasă ocluzală la nivelul dintelui 36

Tratamentul a debutat cu igienizare profesională, constând în detartraj şi periaj profesional, urma- te de restaurarea directă a leziunii carioase. Pentru realizarea propriu-zisă a tehnicii a fost utilizat atât compozit fluid SDR, Dentsply ${ }^{\circledR}$, cât şi un compozit cu consistenţă crescută, condensabil ("packable"): Spectrum Composite, Dentsply ${ }^{\circledR}$.

Etapa următoare de tratament a constat în exereza ţesuturilor alterate şi realizarea unei cavităţi de clasa I ocluzale, extinsă vestibular. Forma, precum şi conturul acesteia sunt specifice pentru materiale adezive, cu unghiuri interne rotunjite (Fig. 2).

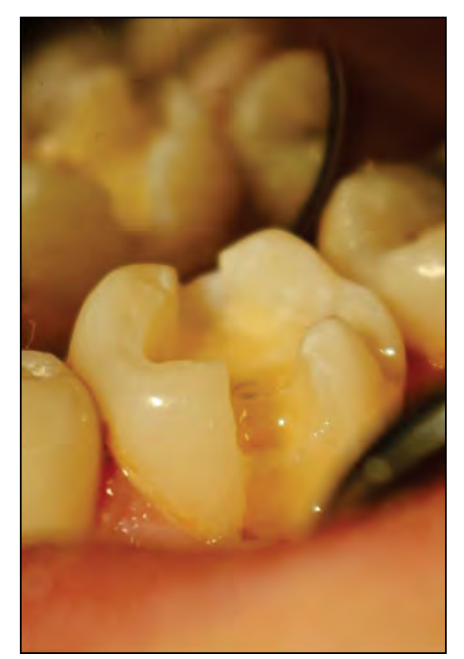

FIGURA 2. Cavitate ocluzo-vestibulară pe dintele 36

În continuare, în vederea inserării materialului compozit prin tehnica bulk fill, dintele a fost izolat, a fost efectuată toaleta cavităţii cu clorhexidină şi au fost realizate etapele specifice de obţinere a adeziunii la ţesuturile dentare: gravaj acid în tehnica "total etch", cu acid orto-fosforic de concentraţie 37\%( Alpha Etch-37R); ulterior spălării şi uscării cavităţii a fost aplicat sistemul adeziv, care a fost fotopolimerizat. Restaurarea odontala directă a debutat cu refacerea peretelui vestibular cu ajutorul compozitului cu consistenţă crescută (Spectrum Composite Dentsply ${ }^{\circledR}$ ), urmată de etapa de inserare a materialului compozit specific pentru tehnica bulk fill(SDR, Dentsply ${ }^{\circledR}$ ) (Fig. 3, Fig. 4).

Pasul următor a fost de inserare a ultimului strat final ocluzal, din material compozit cu consistenţă crescută, acelaşi care a fost utilizat în refacerea peretelui vestibular. Acesta a fost modelat mofologic şi funcţional, ulterior fiind fotopolimerizat.

Ultima etapă de lucru a fost reprezentată de adaptarea în ocluzie a restaurării, folosind intrumentar rotativ diamantat, urmată de finisare şi lustruire, cu ajutorul discurilor abrazive şi a gumelor de lustruit (Fig. 5). 


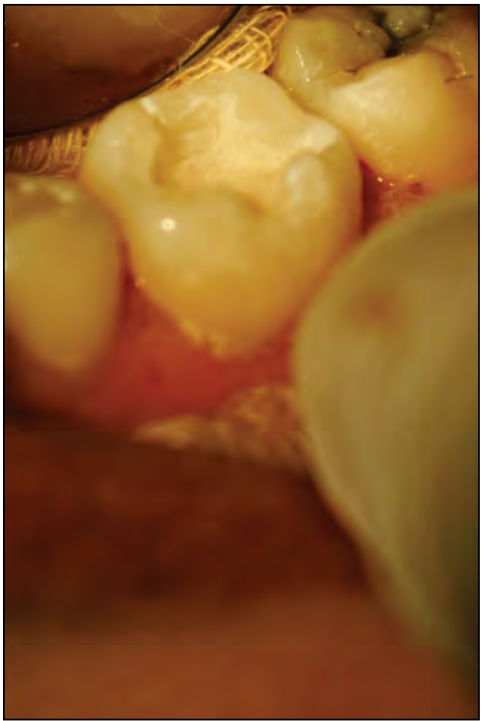

FIGURA 3. Aspectul restaurării după refacerea peretelui vestibular şi inserarea compozitului fluid specific tehnicii bulk fill (vedere vestibulară)

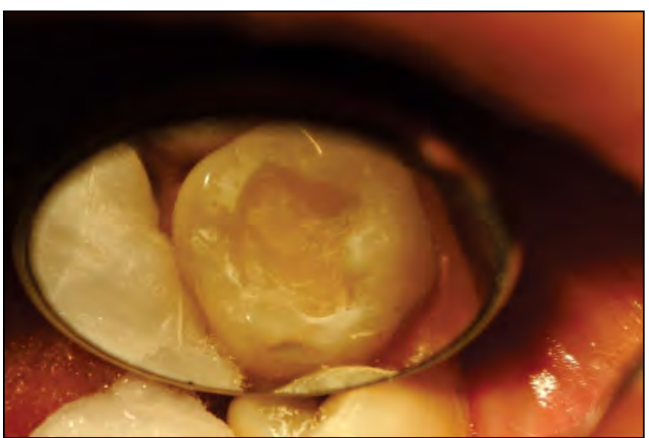

FIGURA 4. Aspectul ocluzal al restaurării după inserarea compozitului bulk fill

\section{BIBLIOGRAFIE}

1. F. Lăzărescu. Incursiune în estetica dentară, Editura SSER Societatea de Stomatologie Estetică din România, Bucureşti, 2013; pg 258; pg 268; pg 261; pg 262; pg 263;

2. Iliescu A, Gafar M. Cariologie şi odontoterapie restauratoare. Ed. Medicala, Bucuresti, 2011, 31-57.

3. Schwendicke F, Göstemeyer G, Blunck U, Paris S, Hsu LY, Tu YK. Directly Placed Restorative Materials: Review and Network Meta-analysis. J Dent Res. 2016 Jun;95(6):613-22.

4. Popa MB, Bodnar DC, Vârlan C. Manual de odontoterapie restauratoare, Volumul I, Editura Universitară „Carol Davila”, Bucureşti, 2007, pg 135; pg. 151-152;

5. Fugolin APP, Pfeifer CS. New Resins for Dental Composites. J Dent Res. 2017 Sep; 96(10):1085-1091.

6. Veloso SRM, Lemos CAA, de Moraes SLD, do Egito Vasconcelos $\mathrm{BC}$, Pellizzer EP, de Melo Monteiro GQ. Clinical performance of bulk-fill and conventional resin composite restorations in posterior teeth: a systematic review and meta-analysis. Clin Oral Investig. 2019 Jan;23(1):221-233.

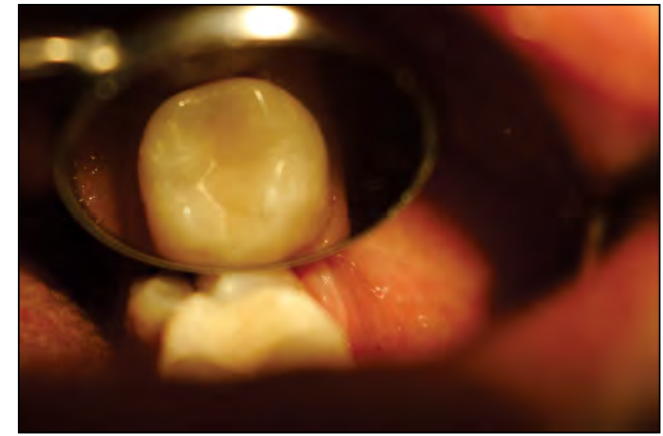

FIGURA 5. Aspectul final al restaurării coronare directe, cu răşini compozite, prin tehnica "bulk fill", la dintele 36

\section{CONCLUZII}

Căutarea unei tehnici ideale de inserare şi modelare a compozitului pentru a atinge excelenţele unei restaurări directe este încă în desfăşurare. Acest deziderat s-ar putea atinge combinând principiile ştiinţifice cu creativitatea artistică a clinicianului, medicul stomatolog alegând materialul şi tehnicile optime pentru situaţia clincă concretă. Tehnica de inserare "în masă" a compozitului ( "bulk fill") se prezintă ca una dintre opţiunile de tratament cele mai promiţătoare pentru viitor.

\section{Menţiune}

Toţi autorii au contribuţie egală în realizarea acestui articol.
7. Bichacho $\mathrm{N}$. The centripetal build-up for composite resin posterior restorations. Pract Periodontics Aesthet Dent. 1994 Apr;6(3):17-23.

8. Karatas O, Bayindir YZ. A comparison of dentin bond strength and degree of polymerization of bulk-fill and methacrylate-based flowable composites. J Conserv Dent. 2018 May-Jun;21(3):285-289.

9. Sawani S, Arora V, Jaiswal S, Nikhil V. Comparative evaluation of microleakage in Class II restorations using open vs. closed centripetal build-up techniques with different lining materials. J Conserv Dent. 2014 Jul;17(4):344-8.

10. Behery H, El-Mowafy O, El-Badrawy W, Nabih S, Saleh B. Gingival microleakage of class II bulk-fill composite resin restorations. Dent Med Probl. 2018 Oct-Dec;55(4):383-388.

11. Haak R, Näke T, Park KJ, Ziebolz D, Krause F, Schneider H. Internal and marginal adaptation of high-viscosity bulk-fill composites in class II cavities placed with different adhesive strategies. Odontology. 2018 Dec 19. doi: 10.1007/s10266-018-0402-1. (Epub ahead of print) 